\title{
Analysis on Development Path of Tianjin Green Logistics
}

\author{
Qiaoli Chang \& Ruiqi Qin \\ Colleges of Economy, Tianjin Polytechnic University, Tianjin 300387, China \\ E-mail: cam80@126.com
}

\begin{abstract}
The logistics serving as Tianjin' pillar industry, to a certain degree, has developed very well, but it still needs to be strengthened. This article not only provides the evaluation standard of green logistics, but also analyzes the Tianjin's present situation in this aspect. At the end of the article, some suggestions are put forward in hope of being helpful to the green logistics develop better and quicker.
\end{abstract}

Keywords: Green logistics, Standard, Path analysis, Present situation

With the rapid development of world economy and modern science, the modern logistics has become a strong growth point of economic development, as well as a nearly established pillar industry in the national economy, namely the development of the green logistics represents both a city's modernization level and its comprehensive strength. Although the logistics promotes economic development, meanwhile, it causes many side effects on city environment, such as noise, gas pollution, traffic jam and improper waste disposal in production and life. Therefore, in the $21^{\text {st }}$ century, we need to meet new requirements of logistic development, namely green logistics.

\section{Concept of green logistics}

The green logistics refers to plan, control, management and implementation the logistics system through the advanced logistics technology and environmental management, aiming to reduce the pollutant emission.

\section{Evaluation standard of the green logistics}

According to the logistics link, the evaluation criterions of enterprise green logistics are as follows:

(1) Green transportation. The green transportation refers to use a kind of fuel with the least pollution as the power to try to implement the multi-transportation and allocation mode. Correctly arrange the transportation can we reduce the pollution, lower the cost and raise the allocation level.

(2) Green storage. The green storage refers to adoption the mechanized operation in the process of goods-storing to save the manpower cost, adoption the environmentally-friendly products to sterilize the storage goods, adoption the method of centralized-stock to reduce the radialization to the surroundings and reduce the adverse effect of the warehousing on the environment.

(3) Green packing. The green package refers to a kind of commodity package that will not cause the environmental pollution. The packing materials should save the resources and reduce the packing waste, moreover, it is supposed to be recycled and regenerated after using, as well as occupies little land while burying in order to be decomposed easily.

(4) Reverse logistics. The reverse logistics is contrary to the traditional supply chain, it devotes to reasonably disposal or recovering the value by planning, managing and controlling the raw materials, middle stock, final products and relative information from consumer place to start point.

(5) Green technology. The green technology refers to adoption the information and communication technology, biological technology, monitoring technology and a variety of specific technologies in the process of logistics management. The application of the advanced technology enables the enterprise to improve management effectively.

According to the logistics environment, the evaluation criterions of city green logistics are as follows:

(1) Green logistics policy. The green logistics policy refers to a series of related policies that the government formulates in the process of implementation of green logistics. On one hand, it can restrict the enterprise's behavior, attempting to comply with the sustainable development goal; on the other hand, it can stimulate the enterprise to implement the green management to conform to the goal which is to construct the harmonious society.

(2) The third party logistics. The third party logistics refers to the enterprises transfer their original logistics activities to specialized service enterprise in the form of commission for concentrating on their principal business., meanwhile, two parties always keep close contract through the information system to effectively manage and control the entire logistics process.

(3) Modern logistics human resource. Under the circumstances of modern logistics, the unified movement of the 
goods, information and fund all in need of careful preparation and implementation, which only the qualified logistics talent could provide, therefore, the modern logistics talent must have solid theoretical foundation and rich in practice experience.

\section{Present situation of green logistics in Tianjin}

(1) In the perspective of the enterprise green logistics, Tianjin has expanded the logistics infrastructures in recent years, which has provided the powerful hardware support for Tianjin's green logistics transportation. According to the investigation that conducted by modern green logistics research center in Nankai university in 2005, it showed that the Tianjin logistics enterprises mainly concentrate on the transportation, loading-unloading, warehousing and allocation, and few enterprises could provide comprehensive service. As for the logistics equipment and technical level, the van trucks accounts for $61.96 \%$, the semi-trailer $21.38 \%$, but the specialization carrier vehicle such as tanker, refrigerated truck are comparatively in a low proportion. The storage facilities that were left behind in the times of plan economy accounts for a large proportion, and most of which still continue to adopt traditional operation mode, while the specialized storehouse or the high-level warehouse, such as insulation warehouse, refrigerated warehouse and top shelf, only accounts for 7.44\%. The enterprises that adopt modern logistics technology GPS and GIS merely accounts for $18.18 \%$. So, in the aspect of enterprise green logistics, Tianjin's logistics enterprise reluctantly conforms to the green transportation, storage and technology standard, but in the other two aspects of green packing and reverse logistics, it still needs improving.

(2) In the perspective of the city green logistics, Tianjin has released many polices to promote the logistics development, what's more, it has formulated many rules and regulations to protect the environment, but it has neglected establishing the green logistics policy, which should combine the logistics industry with the environmental protection together. These years, among the 50 biggest international retail businesses, 2/3 have entered China, such as Wal-Mart, France's Carefour and so on, these groups have set up many logistics distribution centers in Tianjin, and always keeping in line with the logistics concerning purchase. At present, the third party logistics center in Tianjin is still at the embryonic stage. In the aspect of logistics talent, the Tianjin modern logistics investigation shows that among Tianjin more than 20,000 logistics enterprises, the ratio between specialized logistics worked and the total number of staff is $1: 20$, in $51 \%$ logistics enterprises, the proportion of technical staff is below $20 \%$, and about $76.9 \%$ enterprises without a single logistics specialist. So, we can conclude that, in the aspect of city green logistics, the logistics industry merely conforms to the third party logistics standard.

In summary, the Tianjin green logistics is still in a preliminary phase.

\section{Development path of green logistics in Tianjin}

(1) To set up the idea of green logistics. The beginning of green logistics is late in our country. The enterprises do not have adequate awareness for the importance of modern logistics. The establishment of enterprise logistics system mainly sets cost-reducing, benefit-raising and efficiency-improving as the goal. Most of enterprises know very little for the green logistics, some even perceive that "if the environmental protection is not economical, the green means a waste of money". However, nowadays the environmental protection has become more and more important both in international and domestic markets. The enterprises only set up the environmental protection awareness and build green brand can acquire the advantages and obtain the sustainable development in the competition.

(2) To promote logistics informationization and standardization. The ISO14000 are a series of international environment management standards that are formulated by ISO/PTCZOT Environmental Management Committee, which was founded in 1993 by International Standardization Organization. Facing the green revolution waves and green barrier restrictions that formed on the basis of environmental standard competition, our logistics operators are supposed to create the conditions to positively apply for the ISO14000 Standard authentication of environmental management system, making use of the international standard to restrict our own logistics behavior, striving to set up green logistics image, and then enhance our competitiveness in international market. To realize the enterprise logistics informationization, on one hand, is the demand of logistics market and development market, including the mobile demand between market and object, the demand of information, service and technology in logistics activity, on the other hand, it is the enterprise's dependence and demand for logistics market, by this way, the enterprise will improve the logistics efficiency.

(3) To establish reverse logistics system. Microscopically, the reverse logistics has both visible and invisible effects on raising the consumer value, enhancing the competitive advantage, lessening the material cost, increasing the performance, improving the environmental behavior and building the enterprise image. Macroscopically, the reverse logistics is beneficial to the reasonable flowing of social resources; moreover, it can save the resources and improve the sustainable development of environment and economy. Consequently, the enterprise should establish the 
independent logistics departments to manage and coordinate the logistics by the specialists. The specific methods include, firstly, establishing strategy partner with other enterprises on the same supply chain to reduce the unnecessary logistics recycling, secondly, taking recycling into consideration in the production design to control commodity and packing materials rationally, which will facilitate future recycling and regenerating, thirdly, establishing the recycling processing station, combining with the related information like the bar code technology and sort technology to strengthen the management skill.

(4) To strengthen the green logistics research and the personnel-training. For one thing, in view of the deficient theoretical research of logistics in our country, we should make every effort to strengthen the fundamental logistics research. The state Natural Science Fund, the Social Science Fund, the Ministry of Education as well as the Ministry of Technology should enlarge the sponsorship for logistics topic research, stimulating all the enterprises, universities and institutions to cooperate closely, aiming to strengthen the development and application of logistics technology. For another, we should implement the talent strategy positively. Firstly, we should develop the logistics knowledge education vigorously, construct and consummate the multi-level logistics education system to meet the needs of diversification for logistics talent. Secondly, we should strengthen the logistics vocational education to consummate the qualification authentication system. Finally, we should optimize the faculty abilities of logistics education to improve the education quality.

(5) To formulate the logistics environment policy. On one hand, because the logistics activities caused destruction to the environment to a certain extent, so the government should formulate policies to restrain the enterprise's behaviors. Apart from formulating the explicit environmental control standard and method terms, we should also establish the license system and limitation on vacant vehicles to restrain the enterprise or individual behaviors. When formulate the corresponding laws and regulations, we must fully enforce the laws by publishing those enterprises that refuse to implement the green logistics to ensure its stable development. On the other hand, in order to realize the enterprise's green management, the government could formulate the effective green incentive policy, such as subsidy policy, tax policy and government procurement policy, to promote the development of green logistics.

\section{References}

(2007). Tianjjin statistical annual.

Liu, Cuijuan. (2007). Present situation and strategic research of green logistics in Heilongiiang. Heilongjiang transportation science and technology. 8: pp. 97-98

Wang, ling, Li, Kena \& Long, Yangfang. (2005). Questionnaire report on logistics market in Tianjin-supply. Harbor economy. 5: pp. 49-50

Zeng Haizhu. (2007). Discussion on significance and strategy of green logistics in Chengdu area. Logistica management.9: pp. 14-15 